\title{
Preservice Teachers' Evolving View of the Impact of the COVID-19 Pandemic on Online Learning
}

\author{
https://doi.org/10.3991/ijet.v17i04.25923 \\ Xin Bai \\ York College, The City University of New York, NY, USA \\ xbaidyork. cuny. edu
}

\begin{abstract}
The purpose of this study is to investigate preservice teachers' evolving views towards online learning, technological efficacy, and their outlook regarding the strengths and constraints of online learning after a forced transition to online learning during the pandemic of COVID-19. 104 students from two semesters participated in the study. They took Teacher Education as a major or minor. Group 1 was from the Fall semester of 2020. Group 2 was from the following semester of Spring 2021. Group 2 had one more semester of online learning experiences. A mixed-methods design was used to analyze both quantitative and qualitative data from an online survey. Results show preservice teachers' technological self-efficacy and interest increased over time and their attitudes towards online learning became significantly positive. This study provides a concrete understanding of preservice teachers' evolving view towards online education, which could have a critical impact on the adoption of online learning in future $\mathrm{K}-12$ settings.
\end{abstract}

Keywords-pandemic, k-12 online learning, technological efficacy, educational technology

\section{Introduction}

Due to the COVID-19 pandemic lockdown, schools were forced to close overnight. It has transformed the landscape of education in that all the courses had to be offered online (synchronously or asynchronously). Most of those who had a lower level of technical access received accommodations such as computers from the school so that they could continue their online education. This dire situation also created new opportunities for instructors and students to experience and examine online learning as an alternative learning format. This pandemic could redefine education and change future educators' educational beliefs regarding the role of online learning for K-12 students as they leverage these collective lessons to emerge as innovative educators. 


\section{The trend of online learning in higher education before the pandemic of COVID-19}

Online learning in Higher Education has grown dramatically before the pandemic. Almost all public institutions consider online course offerings as part of their critical long-term plans [1]. According to the data from DOE, out of 19.6 million students in the fall of 2019 (right before the pandemic), 7.3 million (37.2\%) students took distance education courses [2]. One reason for the increase is that online learning helps institutions increase recruitment rates by reaching out to more potential students [3]. This is due to its ability to accommodate students' needs by offering flexibility in course attendance so that students could learn anywhere anytime [4]. It helps bridge some educational equity gap especially for the underrepresented population who may have a conflicting work schedule or family responsibilities that may otherwise drop out of school $[5,6]$. However, research also shows that those who were firstgeneration, low income, and non-White had significantly lower levels of technological access (ownership, access to, and usage of computer devices as well as access to Internet services) [7]. There is a positive correlation between technology related access, technological efficacy, and academic outcomes. On the other hand, the quality of teaching is partly dependent on the teacher's technological efficacy [8]. As "technological efficacy scores were significantly lower for students who dropped out of or never enrolled in an online course" [7], providing preservice teachers with the needed technological access for smooth online learning experiences could help address the issue.

Based upon a meta-analysis of more than a thousand empirical studies of online learning between 1996 and 2008, a DOE report shows that "online learning appears to be as effective as conventional face-to-face instruction, but not more so." [9] It also found that "blended instruction combining online and face-to-face elements was more effective than pure online or pure face-to-face instruction" [9]. Meta-analysis of global studies demonstrates "cautious optimism about synchronous hybrid learning which creates a more flexible, engaging learning environment compared to fully online or fully on-site instruction" [10]. However, online learning requires more self-regulation from students [11]. Some administrators still hesitated to recognize online instructions as an effective alternative to face-to-face instructions before the pandemic. Through a case study with 104 participants majoring or minoring in Teacher Education, the study seeks to address the following research questions:

1. How does online learning affect pre-service teachers' technological efficacy on technology over time?

2. Is there a change of attitudes of pre-service teachers towards online learning after more exposure to online learning? 


\section{Methods}

\subsection{Participants}

This study was conducted at a public urban university in New York, which was the epicenter of COVID-19 at the beginning of the pandemic in the United States. The university abruptly switched from mostly traditional face-to-face classes to totally online classes in March of 2020 in the middle of a spring semester. 104 undergraduate students participated in the study in the following two semesters, during which all the classes were offered online. These participants were from two cohorts: Group 1 $(n=48)$ from the Fall semester of 2020; Group $2(n=56)$ from the following Spring semester of 2021. They took the same course, Teaching with Multimedia Technology taught by the same instructor but in different sessions. Group 2 had one more semester of online learning experiences than Group 1. The data collected was part of their regular course activities in the form of self-reflection at the end of the semester. Participation was required, but the participants were recommended to focus on the quality of their responses and they were informed that their positive or negative opinions would not affect their course grade. Institutional Review Board (IRB) was approved to use the student coursework in this study.

\subsection{Data collection and analysis}

Quantitative data are the basis of descriptive and inferential statistics including independent samples t-test, analysis of variance (ANOVA) via SPSS. Student attitudes towards online learning were based upon a 5-point Likert scale ( $1=$ strongly disagree, $5=$ strongly agree). A sample question is "I think effective teaching can be achieved online."

A two-way Analysis of variance (ANOVA) shows the result of the ranked-choice by students. With the most preferred on top (coded as 1) and least preferred at the bottom (coded as 3). The one choice in the middle is coded as 2 .

\subsection{Technological efficacy and interest in technology}

An independent-samples t-test was conducted to determine participants' technological efficacy, interest in technologies, and attitudes towards online learning between two groups - Group 2 has longer exposure (one more semester) to online learning than Group 1.

Both groups reported a fairly high level of technological efficacy in response to the question of "Rate your technical skills as a future teacher" with a 5-star rating. But there was no significant difference in technological efficacy scores for Group $1(\mathrm{M}=$ $3.92, \mathrm{SD}=0.964)$ and Group $2(\mathrm{M}=4.14, \mathrm{SD}=0.749)$ conditions; $\mathrm{t}(102)=-1.345$, $\mathrm{p}=.182$ (Figure 1). The effect size (Cohen's d) is 0.26 . Similarly, both groups reported a fairly high level of interest in technologies in response to the question of "Rate your interest in technologies" with a 5 -star rating, there was also no significant differ- 
ence in scores for Group $1(\mathrm{M}=4.38, \mathrm{SD}=0.890)$ and Group $2(\mathrm{M}=4.50, \mathrm{SD}=$ 0.763 ) conditions; $\mathrm{t}(102)=-.771, \mathrm{p}=.442$ (Figure 1 ). These results suggest that students with online learning experiences develop a high level of technological efficacy and interest in technology. But one more semester of exposure to online learning does not significantly increase the participants' technological efficacy or interest in technology.

\section{Group Statistics}

\begin{tabular}{llr|r|r|r} 
& Group & $\mathrm{N}$ & Mean & $\begin{array}{c}\text { Std. } \\
\text { Deviation }\end{array}$ & $\begin{array}{c}\text { Std. Error } \\
\text { Mean }\end{array}$ \\
\hline $\begin{array}{l}\text { Rate your technical skills } \\
\text { as a future teacher. }\end{array}$ & 1 & 48 & 3.92 & .964 & .139 \\
\cline { 2 - 6 } & 2 & 56 & 4.14 & .749 & .100 \\
\hline $\begin{array}{l}\text { Rate your interest in } \\
\text { technologies. }\end{array}$ & 1 & 48 & 4.38 & .890 & .128 \\
\hline
\end{tabular}

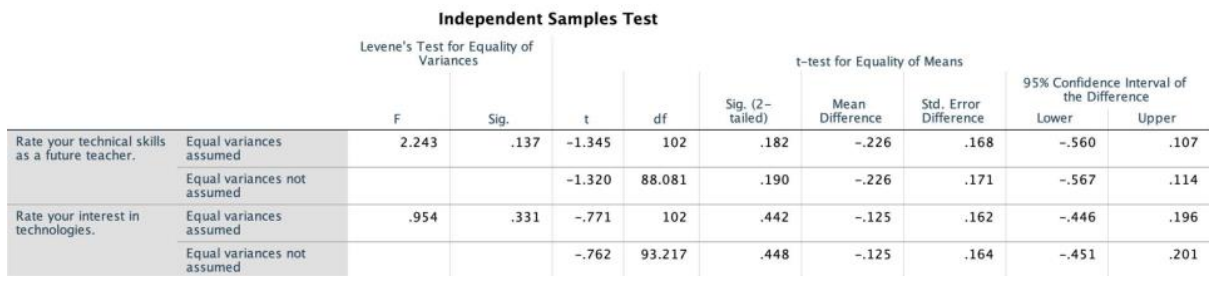

Fig. 1. An independent samples t-test determining whether there was an association between time of exposure to online learning and technological efficacy $(n=104)$

\subsection{Attitudes towards online learning}

An independent samples t-test was run to determine whether there was an association between participants' time exposure to online learning and their attitudes towards face-to-face and online learning based upon 7 Likert-scale questions. The scale ranges from 1 to 5 with 1 as Strongly Disagree, 3 as neutral, and 5 as Strongly Agree.

There is a higher score for Group $2(\mathrm{M}=4.11, \mathrm{SD}=0.966)$ than for Group $1(\mathrm{M}=$ $3.75, \mathrm{SD}=1.12$ ) in response to the statement "I enjoyed real-time online class sessions." But the difference is not statistically significant. Therefore, the results suggest that both groups enjoyed real-time online class sessions.

However, data show a significant difference between the two groups in response to the rest of the questions as follow (Figure 2):

- In response to the statement "Online classes allowed more flexibility in their learning schedule", there is a significant difference in the scores for Group $2(\mathrm{M}=4.64$, $\mathrm{SD}=.724)$ and Group $1(\mathrm{M}=3.98, \mathrm{SD}=1.062) ; \mathrm{t}(102)=-3.662, \mathrm{p}<.001$. The effect size (Cohen's $d=0.74$ ) is fairly large. The result suggests that when students are exposed to online learning longer, their attitude towards the flexibility that online learning offers becomes more positive. 
- In response to the statement "learning online helps develop more confidence in technology", there is a significant difference in the scores for Group $2(\mathrm{M}=4.48$, $\mathrm{SD}=.713)$ and Group $1(\mathrm{M}=4.08, \mathrm{SD}=.919) ; \mathrm{t}(102)=-2.490, \mathrm{p}=.014$. The effect size (Cohen's $d=0.49$ ) is medium. The result suggests that when students are exposed to online learning longer, their technological confidence increases.

- In response to the statement "I prefer less to face-to-face and more to online learning", there is a significant difference in the scores for Group $2(\mathrm{M}=3.3, \mathrm{SD}=$ 1.278) and Group $1(\mathrm{M}=4.08, \mathrm{SD}=1.028) ; \mathrm{t}(102)=3.390, \mathrm{p}=.001$. The effect size (Cohen's $d=0.67$ ) is fairly large. The result suggests that when students are exposed to online learning longer, they prefer less to face-to-face and more to online learning.

- In response to the statement "I think face-to-face learning is important for effective teaching", there is a significant difference in the scores for Group 2 (M = 3.64, SD $=1.052)$ considered than Group $1 \mathrm{did}(\mathrm{M}=4.25, \mathrm{SD}=.911) ; \mathrm{t}(102)=3.120, \mathrm{p}=$ .002 . The effect size (Cohen's $d=0.82$ ) is large. The result suggests that when students are exposed to online learning longer, they consider face-to-face learning as less important for effective teaching than before.

- In response to the statement "I think effective teaching can be achieved online", there is a significant difference in the scores for Group $2(\mathrm{M}=4.48, \mathrm{SD}=.713)$ agreed more with the statement that than Group 1 did $(\mathrm{M}=4.08, \mathrm{SD}=.919) ; \mathrm{t}$ $(102)=-2.490, p=.014$. The effect size (Cohen's $d=0.37$ ) is close to medium. The result suggests that when students are exposed to online learning longer, they become more positive that effective teaching can be achieved online.

- In response to the statement "I plan to choose more hybrid/online classes after the pandemic", there is a significant difference in the scores for Group $2(\mathrm{M}=4.09$, $\mathrm{SD}=1.10)$ indicated more willingness to than Group $1 \mathrm{did}(\mathrm{M}=3.31, \mathrm{SD}=1.24)$; $t(102)=-3.385, p=.001$. The effect size (Cohen's $d=0.67)$ is fairly large. The result suggests that when students are exposed to online learning longer, they are more willing to choose hybrid/online classes after the pandemic. 


\section{Group Statistics}

\begin{tabular}{|c|c|c|c|c|c|}
\hline & Group & $\mathrm{N}$ & Mean & $\begin{array}{l}\text { Std. } \\
\text { Deviation }\end{array}$ & $\begin{array}{c}\text { Std. Error } \\
\text { Mean }\end{array}$ \\
\hline \multirow{2}{*}{$\begin{array}{l}\text { I enjoyed real-time } \\
\text { online-class sessions }\end{array}$} & 1 & 48 & 3.75 & 1.120 & .162 \\
\hline & 2 & 56 & 4.11 & .966 & .129 \\
\hline \multirow{2}{*}{$\begin{array}{l}\text { Online classes allowed } \\
\text { flexibility in my learning } \\
\text { schedule }\end{array}$} & 1 & 48 & 3.98 & 1.062 & .153 \\
\hline & 2 & 56 & 4.64 & .724 & .097 \\
\hline \multirow{2}{*}{$\begin{array}{l}\text { Learning online helped } \\
\text { me develop confidence } \\
\text { in technology. }\end{array}$} & 1 & 48 & 4.08 & .919 & .133 \\
\hline & 2 & 56 & 4.48 & .713 & .095 \\
\hline \multirow{2}{*}{$\begin{array}{l}\text { I prefer face-to-face to } \\
\text { online learning. }\end{array}$} & 1 & 48 & 4.08 & 1.028 & .148 \\
\hline & 2 & 56 & 3.30 & 1.278 & .171 \\
\hline \multirow{2}{*}{$\begin{array}{l}\text { I think face-to-face } \\
\text { learning is important for } \\
\text { effective teaching. }\end{array}$} & 1 & 48 & 4.25 & .911 & .131 \\
\hline & 2 & 56 & 3.64 & 1.052 & .141 \\
\hline \multirow{2}{*}{$\begin{array}{l}\text { I think effective teaching } \\
\text { can be achieved online. }\end{array}$} & 1 & 48 & 3.54 & .922 & .133 \\
\hline & 2 & 56 & 3.89 & .947 & .127 \\
\hline \multirow{2}{*}{$\begin{array}{l}\text { I plan to choose more } \\
\text { hybrid/online classes } \\
\text { after the pandemic. }\end{array}$} & 1 & 48 & 3.31 & 1.240 & .179 \\
\hline & 2 & 56 & 4.09 & 1.100 & .147 \\
\hline
\end{tabular}

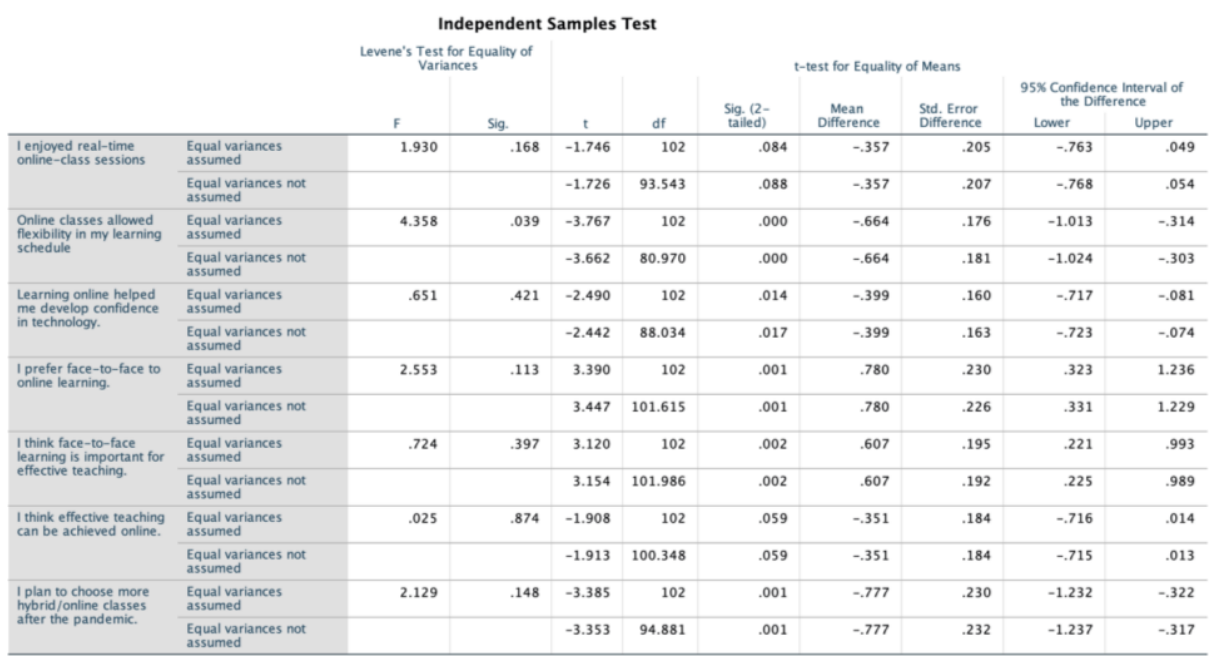

Fig. 2. An independent samples t-test determining the attitudes of participants towards face-toface and online learning $(n=104)$

\subsection{Student preferences among the face-to-face, hybrid, and online learning formats}

A two-way analysis of variance (ANOVA) was conducted on the influence of two independent variables (group, course format) on the ranked order of course formats. 
Group included two levels (Group 1 and Group 2); Group 2 had one more semester of exposure to online learning than Group 1). Course format consisted of three levels (face-to-face, hybrid, online). All effects were statistically significant at the .05 significance level except for the Group factor. The main effect for Group yielded an F ratio of $\mathrm{F}(1,306)=.00, p=1$, indicating that the effect for group was not significant, Group $1(\mathrm{M}=2, \mathrm{SD}=.819)$ and Group $2(\mathrm{M}=2, \mathrm{SD}=.819)$. This is as predicted as the mean of the 3 ranked order items is always 2 for both groups. The main effect for course format yielded an $\mathrm{F}$ ratio of $\mathrm{F}(2,306)=5.849, p=.003$, indicating a significant difference between Face-to-face $(\mathrm{M}=2.0, \mathrm{SD}=.892)$, Hybrid $(\mathrm{M}=1.84, \mathrm{SD}=$ $.609)$ and Online $(\mathrm{M}=2.16, \mathrm{SD}=.893$. The interaction effect was significant, $\mathrm{F}(2$, $306)=24.724, p<.001$ (Figure 4 ). The result suggests that when students are exposed to online learning longer, they are more willing to choose online classes after the pandemic as opposed to face-to-face learning. The attitudes towards hybrid learning remained consistent.

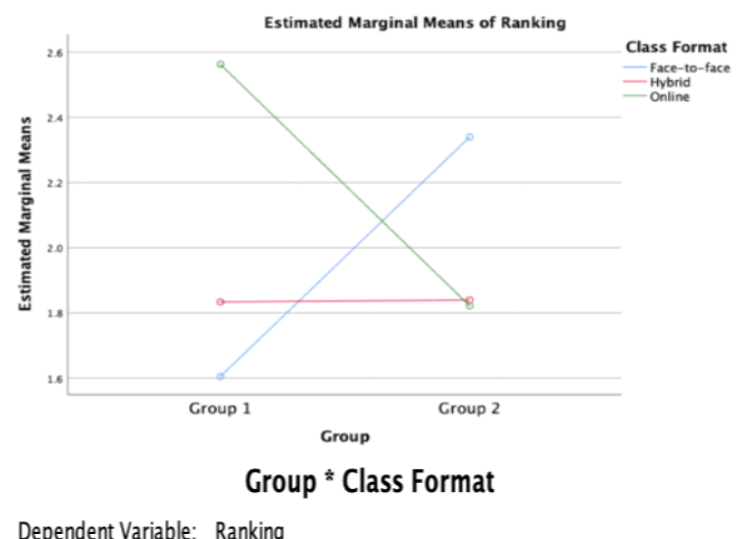

\begin{tabular}{ll|l|r|r|r}
\multicolumn{2}{c}{ Dependent Variable: Ranking } & \multicolumn{3}{c}{} \\
\multirow{2}{*}{ Group } & Class Format & Mean & Std. Error & Lower Bound & Upper Bound \\
\hline Group 1 & Face-to-face & 1.604 & .109 & 1.390 & 1.819 \\
\cline { 2 - 7 } & Hybrid & 1.833 & .109 & 1.619 & 2.048 \\
\cline { 2 - 7 } & Online & 2.563 & .109 & 2.348 & 2.777 \\
\hline Group 2 & Face-to-face & 2.339 & .101 & 2.141 & 2.538 \\
\cline { 2 - 7 } & Hybrid & 1.839 & .101 & 1.641 & 2.038 \\
\cline { 2 - 7 } & Online & 1.821 & .101 & 1.623 & 2.020 \\
\hline
\end{tabular}

Fig. 3. Ranked choice means of the 3 class formats (face-to-face; hybrid; online) by Group 1 and Group $2(\mathrm{n}=104)$ 
Tests of Between-Subjects Effects

\begin{tabular}{|c|c|c|c|c|c|c|}
\hline \multicolumn{7}{|c|}{ Dependent Variable: Ranking } \\
\hline Source & $\begin{array}{l}\text { Type III Sum } \\
\text { of Squares }\end{array}$ & $\mathrm{df}$ & Mean Square & $\mathrm{F}$ & Sig. & $\begin{array}{c}\text { Partial Eta } \\
\text { Squared }\end{array}$ \\
\hline Corrected Model & $33.720^{\mathrm{a}}$ & 5 & 6.744 & 11.841 & .000 & .162 \\
\hline Intercept & 1240.615 & 1 & 1240.615 & 2178.270 & .000 & .877 \\
\hline Group & .000 & 1 & .000 & .000 & 1.000 & .000 \\
\hline Format & 6.663 & 2 & 3.331 & 5.849 & .003 & .037 \\
\hline Group * Format & 28.163 & 2 & 14.081 & 24.724 & .000 & .139 \\
\hline Error & 174.280 & 306 & .570 & & & \\
\hline Total & 1456.000 & 312 & & & & \\
\hline Corrected Total & 208.000 & 311 & & & & \\
\hline
\end{tabular}

a. R Squared $=.162$ (Adjusted R Squared $=.148)$

Fig. 4. A two-way analysis of variance (ANOVA) was conducted on the influence of two independent variables (group, course format) on the ranked order of course formats

\subsection{Qualitative analysis of the comments from the participants}

Below is the analysis of the responses on the pros and cons of online learning regarding the following question: "How do you perceive online learning during the pandemic? Describe both the pros and cons based upon your observations and your personal experiences." Figure 5 shows the percentage frequency (i.e., frequency/total group number) of each theme for Group 1 (G1) and Group 2 (G2).

Pros were broadly categorized into 10 themes (flexibility; commute; Save time/money; better communication online; more responsible; more focused; more confident in tech; safe for health; re-watch video; get/receive family support). Group 2 had one more semester of exposure to online learning than Group 1 during the pandemic. They appreciated more about the flexibility that online learning offers (G1:54\% vs. G2: 68\%); they also reported better online communication experiences (G1:8\% vs. G2: $16 \%$ ); they learned to be more responsible (G1:6\% vs. G2: $21 \%$ ); and enjoyed getting or receiving family support through this learning format (G1:4\% vs. G2: 14\%); The response percentages for the rest of the positive themes were similar.

Cons were broadly categorized into 9 themes (difficult to collaborate; cheating; ineffective communication; tech issue; distraction; ineffective teaching; time management issue; stress, anxiety, health issues; less motivated). Group 2 reported less percentage of ineffective communication (G1:52\% vs. G2: 36\%); ineffective teaching (G1:35\% vs. G2: 9\%); stress, anxiety, and health related issues (G1:23\% vs. G2: 9\%) and tech issues (G1:33\% vs. G2:27\%). The response percentages for the rest of the negative themes were similar. 


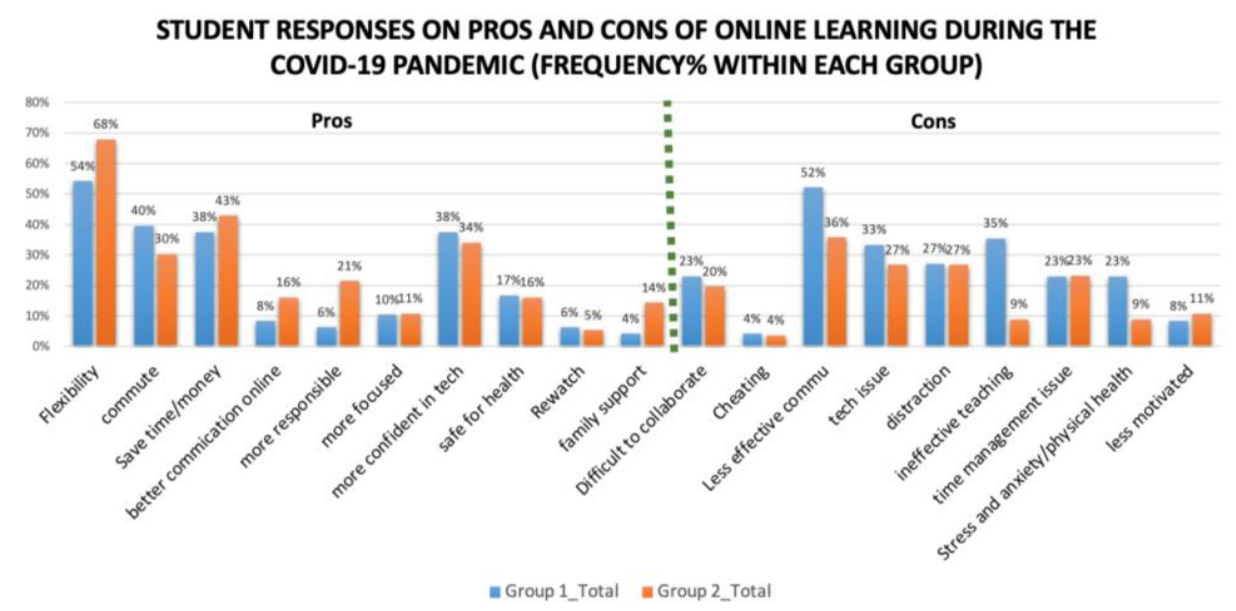

Fig. 5. Percentage of response frequency (i.e., frequency of each theme/total group number) regarding the pros and cons of online learning Group $1(\mathrm{n}=48)$; Group $2(\mathrm{n}=56)$

\section{Discussion}

4.1 How does online learning affect pre-service teachers' technological efficacy on technology over time?

Based upon triangulated data from 5-star rating questions, Likert-scale questions, and open-ended questions, our study shows that students with online learning experiences develop a high level of technological efficacy and interest in technology. Although the results from the 5-star rating questions did not show statistical differences between the two groups that have different time exposure to the online learning experience, the 7 Likert-scale questions showed that one more semester of exposure to online learning significantly increased the participants' technological efficacy and interest towards technology. In response to the opened-ended questions regarding the pros and cons of online learning, a high percentage of participants from both groups reported that they felt more confident in technology. As some students from Group 1 commented:

- [Online Learning] helped me become more of an independent learner and helped me to think of technology as a friend rather than being an intimidating thing.

- The positive factors of online learning for me are gaining confidence with using technology. It also allowed me to use online software to help me become creative when teaching in a classroom.

- Also studying online I have known, explored and learned to use the different platforms that have been essential for my online learning. Platforms such as Zoom, [Blackboard] Collaborate ultra, google meets, google hangouts among others. 
- Distance learning is good as it helps students to increase their mastery and competency of tech and learn about new innovative tools that will serve them greatly in the professional world.

Responses from Group 2 were more specific:

- I have become well versed with using technology-based platforms which is a plus because these platforms I can use when I become a teacher.

- I feel as though I have improved technological wise and also it has helped me feel more independently responsible about my academics (discussion board, assignments, etc.).

- After earning about technology for learning during my education class, I came to the assumption that online learning would benefit older students such as high schoolers and college students. I think the elementary school level will benefit from hybrid or face-to-face until they are completely knowledgeable of the technology.

- teaches everyone more about technology. Technology is constantly developing, so it is useful to know these things.

- I've learned how to use different types of technology and push myself to become much more familiar with them.

- This experience has taught me how to use technology properly, manage my procrastination habits and value education in all shape or form.

- In response to the rapidly evolving advances and dependency of technology in the professional world, remote learning poses teachers the advantage of educating their students within the online platforms -- and same resources -- that they will be required to use later on in their different professions. While also allowing teachers to evaluate his/her students differently through numerous online assessments and more, it also permits users to establish his/her own schedule adapting it to his/her needs.

- It made me develop more computer skills. Before the pandemic, I had virtually no computer literacy. But, online made it inevitable that I must develop computer skills because that was the only way I could keep up with my academic work.

Prior research [12] shows teachers have a lower level of self-efficacy about online teaching due to a lack of online learning experiences. Due to the pandemic, more exposure to online learning has increased pre-service students' technological selfefficacy over time. With more confidence, these future teachers could be leaders in the K-12 classrooms in promoting online learning for students to gain access to education anytime anywhere.

\subsection{Is there a change of attitudes of pre-service teachers towards online learning after more exposure to online learning?}

Based upon triangulated data from rating questions, Likert-scale questions, and open-ended questions, our study not only shows that pre-service teachers felt more and more confident with an interest in technology, they appreciated more about the 
flexibility that this format of learning offers. The majority of students $(68 \%)$ mentioned flexibility as the advantage of online learning. Most of these students are economically disadvantaged. Some of them have multiple jobs, others had to take care of their children or sick family members themselves. Online learning provided them with equitable learning opportunities that they cannot have otherwise. As one participant mentioned, "I did not want to be late for class so I decided to park at a convenient location [to attend the class from phone]". Such flexibility also allows them to resolve the commute issue, thus saving time or money, which are two other mostly mentioned themes. With more exposure to online learning, students reported less stress, anxiety, and health-related sickness (such as eye, back issues) (G1: 23\% vs. G1: $9 \%)$.

Another important finding is instructors seemed to have improved their teaching competencies as well. Students' report of ineffective teaching decreased from $35 \%$ to $9 \%$. At the beginning of the pandemic, when all the instructors were forced to teach online, many of them had never taught online before. Students expressed frustrations and confusion. Some couldn't see the professor's face, while others reported that the instructor was only reading lecture notes without interactions. The reason could be, as the instructors gain more online teaching experiences through varied professional development opportunities offered by the college, they could have developed more effective teaching strategies. In the future, their willingness to adopt online or hybrid teaching might increase. As observed by the anecdotal accounts from the author's colleagues, more and more instructors from this public university would like to offer hybrid/online classes in the future. This will in turn expose future pre-service teachers to more online learning experiences. Thus, a new culture of online learning emerges.

"Less effective communication" was the most mentioned theme regarding the cons of online learning. Students expressed frustrations about not being able to connect with other students, teachers, or school staff. This will continue to be a challenge for future studies. Face-to-face communication is still considered the most effective way of making connections to other people. As one of the participants commented, "attempting to chime in during online class discussions is nerve-wracking." On the other hand, some students found online communication was a better approach - "[online learning] helped shy students like myself feeling more confident to speak behind a screen. I felt very open and willing to participate more rather than just staying to myself in a physical classroom." Will we ever find an effective online alternative to replace face-to-face communication?

Technical issues are still an ongoing problem. Students reported difficulties with Internet connection or software malfunction glitches. Although the college provided computer equipment, lots of students still struggled. Some of them shared the internet with siblings during school time, others were constantly kicked out of the virtual classroom or the mic malfunction. Some had to use a phone instead of a computer as a Plan B. Schools should continue to provide technical support and equipment to these students to avoid creating a digital divide due to computer access to online classrooms.

Many students (27\% from both groups) reported that it's easier to be distracted while taking online classes. Some took the class while having dinner with family. 
Some took classes in pajamas in bed. Sometimes their kid(s) might interrupt the classes. This also enacts positive changes. More students (G2: $21 \%$ vs. G1: $6 \%$ ) reported that became more responsible. Some designed better self-regulation strategies. For instance, working from a desk instead of a bed, and manage the schedule more carefully. Still, many students (23\% from both groups) continued to have time management issues. They commented, without the push in a face-to-face setting, they might sometimes forget to complete schoolwork on time. $8-11 \%$ of responses from both groups reported that they were less motivated learning online. Effective teaching strategies need to be explored to engage these students.

\section{Conclusion}

Based upon the findings of this study, it was concluded that pre-service teachers' technological self-efficacy increased due to more exposure to online learning. They also became more interested in technology. Their attitudes towards learning modality changed - they preferred online learning and hybrid learning more than face-to-face learning; while, at the beginning of the pandemic, face-to-face learning was the most preferred learning format. Preservice teachers also developed more positive attitudes towards online learning due to its flexibility and its ability to help them save time/money and avoid commute issues. Their reported stress, anxiety levels, and health-related issues also decreased.

Although effective online communication remained an issue, preservice teachers reported more positive learning experiences over time. They developed coping skills and became more responsible and organized. College instructors' teaching was reported by the students to be more effective over time. We could foresee a future with more instructors willing to offer online courses. This could in turn attract more underrepresented, economically disadvantaged students back to school for a better chance of social mobility.

Some issues remain despite of more exposure to online learning. More research is needed to investigate how to help students develop time management skills and build strategies to stay focused online. Educators need to continue to explore pedagogies to motivate and engage students through providing effective online communication and facilitating peer collaboration online.

\section{References}

[1] Major, C. H. (2010). Do virtual professors dream of electric students? University faculty experiences with online distance education. Teachers College Record, 112(8), 2154-2208. https://doi.org/10.1177/016146811011200802

[2] Digest of Education Statistics. (2020). U.S. Department of Education, National Center for Education Statistics, Integrated Postsecondary Education Data System (IPEDS). Retrieved on 07/10/2021 from https://nces.ed.gov/programs/digest/d20/tables/dt20_311.15.asp

[3] Wang, Q., Quek, C. L., \& Hu, X. (2017). Designing and improving a blended synchronous learning environment: An educational design research. International Review of Research 
in Open and Distributed Learning, 18(3), 99-118. https://doi.org/10.19173/irrodl.v18i3.30 $\underline{34}$

[4] Beatty, B. J. (2007). Transitioning to an Online World: Using HyFlex Courses to Bridge the Gap. In C. Montgomerie \& J. Seale (Eds.), Proceedings of ED-MEDIA 2007--World Conference on Educational Multimedia, Hypermedia \& Telecommunications (pp. 27012706). Vancouver, Canada: Association for the Advancement of Computing in Education (AACE). Retrieved on June 18, 2021 from https://www.learntechlib.org/primary/p/25752/

[5] Lightner, C. A., \& Lightner-Laws, C. A. (2016). A blended model: Simultaneously teaching a quantitative course traditionally, online, and remotely. Interactive Learning Environments, 24, 224-238. https://doi.org/10.1080/10494820.2013.841262

[6] Liu, H., Spector, J. M., \& Ikle, M. (2018). Computer technologies for model-based collaborative learning: A research-based approach with initial findings. Computer Applications in Engineering Education, 26(5, SI), 1383-1392. https://doi.org/10.1002/cae.22049

[7] Banerjee, M. (2020). An exploratory study of online equity: differential levels of technological access and technological efficacy among underserved and underrepresented student populations in higher education. Interdisciplinary Journal of e-Skills and Lifelong Learning, 16, 93-121. https://doi.org/10.28945/4664

[8] Bower, M., Dalgarno, B., Kennedy, G. E., Lee, M. J. W., \& Kenney, J. (2015). Design and implementation factors in blended synchronous learning environments: Outcomes from a cross-case analysis. Computers \& Education, 86, 1-17. https://doi.org/10.1016/j.compedu. 2015.03.006

[9] Means, B., Toyama, Y., Murphy, R., Bakia, M., \& Jones, K. (2010). Evaluation of evidence-base practices in online learning: A meta-analysis and review of online learning studies. Washington, DC: Department of Education Office of Planning, Evaluation, and Policy Development.

[10] Raes, A., Detienne, L., Windey, I. et al. A systematic literature review on synchronous hybrid learning: gaps identified. Learning Environ Res 23, 269-290 (2020). https://doi.org/10 $.1007 / \mathrm{s} 10984-019-09303-\mathrm{z}$

[11] Wiles, G. L., \& Ball, T. R. (2013, June 23-26). The converged classroom. Paper presented at ASEE Annual Conference: Improving course effectiveness, Atlanta, Georgia. https://pe er.asee.org/22561

[12] Devica, S. (2015). Teacher perceptions of efficacy in the secondary virtual classroom: A phenomenological study. City University of Seattle.

\section{$7 \quad$ Author}

Xin Bai is an Associate Professor at Department of Teacher Education, York College of the City University of New York, NY, USA.

Article submitted 2021-08-02. Resubmitted 2021-12-03. Final acceptance 2021-12-21. Final version published as submitted by the author. 